\title{
Editorial
}

\section{A corrida e seus limites}

\author{
Jean-Louis Peytavin
}

Qual é a limite do treinamento em jogging e corrida? O maratonista vive mais tempo do que o sedentário diabético e hipertenso? Temos que limitar o tempo da corrida diária? A resposta parece óbvia, mas não tanto: na verdade não existem estudos definitivos sobre o assunto e não sabemos ainda se treinar para o Ironman é uma boa ideia no que se refere à longevidade.

Um estudo recente [1], realizado na Dinamarca, acompanhou um grupo de 1098 corredores e de 413 pessoas sedentárias, mas saudáveis, participantes de um estudo sobre as doenças cardiovasculares, com ajustes por idade, sexe, educação, diabetes e saúde cardiovascular. Geralmente, os corredores eram mais jovens, menos fumantes e diabéticos, com IMC e pressão arterial mais baixos do que os sedentários. Após 12 anos de acompanhamento, o estudo concluiu que os praticantes mais leves, os que correm entre 1 e 2,4 horas por semana, divididas em 3 sessões, são os que apresentam o menor risco de mortalidade, todas causas confundidas. $\mathrm{O}$ risco de mortalidade aumenta com o treino semanal e os praticantes mais assíduos apresentam ao final a mesma taxa de mortalidade do que os sedentários. Os autores concluem que atividade física reduziu o risco de morte de $30 \%$ (ou ganho de 5 a 6 anos de vida segundo outro estudo) em relação às pessoas sedentários, e que o maior ganho de longevidade se encontra do lado da atividade leve, tipo jogging. Isso se explicaria pela intensidade do esforço cardíaco na corrida e pelo risco de distúrbios do ritmo cardíaco, principalmente de fibrilação auricular em caso de treinamento intenso.

\section{Referências}

1. Schnohr P, O'Keefe JH, Marott JL, Lange P. Jensen GB. Dose of jogging and long-term mortality The Copenhagen City Heart Study. J Am Coll Cardiol 2015;65(5):411-9.

\section{AVISO AO ASSINANTE}

A Atlântica Editora lançou sua primeira revista científica Fisioterapia Brasil há 16 anos, e que se tornou referência no meio profissional. No decorrer dos anos seguiram mais seis revistas científicas. Apesar do reconhecimento acadêmico e profissional, tivemos algumas dificuldades durante esses anos, motivadas pelo aumento dos custos de produção gráfica, dos envios postais, do custo de participação em congressos e eventos, bem como a ausência total de incentivo fiscal e dos correios, ao contrário de que se passa em outros países, onde a edição e a divulgação científica são altamente favorecidas.

Em razão de mudanças e de reorganização na direção da Editora, alteramos o ritmo de publicação de algumas revistas para colocar as ediçóes em dia. Isso não muda a vigência de sua assinatura ora contratada, que inclui sempre 6 a 12 ediçóes até o término de seu contrato

Continuaremos regularmente com nossas publicaçôes, mantendo nossa qualidade editorial e científica. Aproveitamos para agradecer a compreensão de todos os nossos autores, assinantes e leitores. 